\title{
The Hungarian palatal stop: Phonological considerations and phonetic data
}

\author{
Christian Geng \\ ZAS Berlin
}

Christine Mooshammer

University of Kiel

This study examines the movement trajectories of the dorsal tongue movements during symmetrical / $\mathrm{VCa}$-sequences, where /V/ was one of the Hungarian long or short vowels $/ \mathrm{i}, \mathrm{a}, \mathrm{u} / \mathrm{and} \mathrm{C}$ either the voiceless palatal or velar stop consonants. General aims of this study were to deliver a data-driven account for (a) the evidence of the division between dorsality and coronality and (b) for the potential role coarticulatory factors could play for the relative frequency of velar palatalization processes in genetically unrelated languages. Results suggest a clear-cut demarcation between the behaviour of purely dorsal velars and the coronal palatals. Morevover, factors arising from a general movement economy might contribute to the palatalization processes mentioned.

\section{Introduction}

The palatal stop has been a matter of debate for at least two reasons: first it is not clear whether it is articulated with a dorsal component, which would involve the specification as a complex segment. The concurrent specification would favour a classification as simple coronals and introduce at least one additional feature to separate them from the other [-anterior] coronals (Keating, 1991). Secondly, on a phonetic level, the relationship of the palatal stop to the velars remains unclear (Recasens, 1990).

The data analyzed in the phonological discourse related to the notion of distinctive features has mainly utilized static X-Ray-images, linguo- and palatograms to determine a featural description of palatal articulation. In contrast, the research work which has studied palatal articulation from the phonetically motivated viewpoint of lingual coarticulation has mainly relied on electropalatographic data, which has the merit of supplying time-varying data but only if there is a contact 
and with the drawback of a very limited spatial interpretability. The first aim of this study is to give a descriptive account of the articulatory realization of palatal stops by making use of movement data acquired by the articulograph.

In recent years, the influence of phonetic mechanisms in shaping the paradigmatic contrasts of a language has been refocused by the scientific community, as articulatory economy, perceptual discriminability and the maintenance of contrast have been agreed on as the key phonetic factors shaping the sound inventories of the world's spoken languages. For the palatal articulation we are dealing with this involves the reference to the natural phonological process of (velar) palatalization, and therefore the comparison of the palatal stop articulation with the stop articulation at the velar place of articulation. Therefore, in the current study we relate the palatal to the velar stop articulation of the same language to explore the articulatory economy principles governing the palatal/velar or coronal/dorsal contrast

The introduction is structured as follows: we will first summarize phonetic approaches for explaining sound change in general, taking palatalization processes as a concrete example. ${ }^{1}$ We will see that these refer to different parts of the phonetic band and partially make reference to a clear-cut-distinction between true assimilative change and coarticulatory variation. It will turn out that more recent approaches assign a more prominent role to coarticulatory variation than did the generative tradition. We will then summarize selected approaches to coarticulation and the different predictions they make about the concrete data we collected.

\subsection{Accounts of phonetically induced sound change}

Several accounts of phonetic sound change have been proposed in the literature. The main distinction between them lies in the identification of the factors by which they are driven: Is the primary principle rooted in articulation, acoustics/perception or a kind of transaction between these two kinds of influences. Let us exemplify these different standpoints on the basis of a subprocess of an extensively studied phonological process, palatalization. According to Bhat (1978), at least three distinct processes contribute to palatalization processes, and Bhat presents these as independent subprocesses of palatalization: These are tonguefronting, tongue-raising and spirantization. Of special concern here is the the fronting of velars conditioned by the presence of a front vowel, i.e.

\footnotetext{
${ }^{1}$ Note that the term palatalization has a different meaning in phonetics/phonology: it denotes the addition of a secondary palatal articulation to a primary articulation, like in palatalized labials. Here, the term palatalization is used in the way it is used in typology or historical linguistics, i.e. as a phonological process (Bhat, 1978).
} 


\section{$[\mathrm{k}] \quad \rightarrow \quad[\mathrm{c}] \quad / \quad \ldots$}

As mentioned, accounts in the neo-grammarian tradition would seek for articulatory factors underlying the fronting of the velar in front vowel context. A contemporary theorist following this rationale is Recasens. He views palatalization as a gradual sound change mechanism proceeding from the unstable mediopostpalatal or medio-palatal articulations towards preferred alveolopalatal ones through an increase in predorsal and laminal contact (Recasens, 2003).

An approach relying primarily on acoustic properties of the speech signal is the theory and research program of acoustic invariance (Blumstein \& Stevens, 1979), which was elaborated in a series of papers (Lahiri \& Blumstein, 1984; Blumstein, 1986; Keating \& Lahiri, 1993). This theory makes the claims that (1) there is acoustic invariance in the speech signal corresponding to the phonetic features of a language (Blumstein, 1986, p. 178) and that (2) the perceptual system is sensitive to these invariant properties. These invariant properties are seen responsible for the natural processes in phonology, and, in particular can account for why certain "assimilation rules" are more likely to occur. The conditions for the occurrence of an assimilation (Blumstein, 1986, p. 186) are (a) that the two contiguous segments must have some similar acoustic properties and (b) that the original sound and the modified sound must also share a number of acoustic properties. In the case of velar fronting the acoustic property of the segments involved are identified as the relative distribution of energy: Palatals exhibit a selective increase in energy between burst and voicing onset in the frequency band between 800 and $1800 \mathrm{~Hz}$, whereas the distribution for velars is comparatively "flat".

In other words, "the assimilation of [k] to [c] involves a true assimilation of the acoustic property of gravity from the vowel to the preceding consonant" (Blumstein, 1986, p. 186). In short, this kind of theorizing views the sound change under consideration as a true assimilative change by making reference to revived Jakobsonian featural descriptions.

The third class of theories emphasizes the use of perceptual factors for sound change. Among these are -on a metatheoretical level- the scenarios of generalizing mini sound changes as elaborated by Ohala (e.g. Ohala (1983), Ohala (1993)) and Lindblom's approach of adaptive dispersion (Lindblom et al., 1995). A concrete instantiation of Lindblom's approach is carried out in the work of Guion (1998): She interprets the facts about velar palatalization in terms of a perceptual reanalysis of fast speech. On a large scale, we see the explananda in the potential influence and interaction of these factors in shaping language change, and for the present purpose, in an exploration of its articulatory antecedentia.

\footnotetext{
2/i/ has F2 und F3 in the same region.
} 


\subsection{Theoretical Approaches to coarticulation}

Classical generative theory makes a clearcut separation between coarticulation and other context-dependent phenomena, such as assimilations: Coarticulation deals with "transitions between vowels and adjacent consonants, the adjustments in the vocal tract shape made in anticipation of a subsequent motion" (SPE:295, after Farnetani \& Recasens (1999)) In contrast, assimilations involve operations on phonological features, and are accounted for by phonological rules, which map lexical representations onto phonetic representations. This kind of reasoning comprises the acoustic invariance approach relying on Jakobsonian ideas as well as the approach taken in SPE with extensive marking conventions. We skip a more thorough discussion as these approaches are not laid out to make more detailed predictions about articulatory surface behavior ${ }^{3}$ : Coarticulation and other properties of phonetic implementation are assumed to follow from universal principles of speech physiology.

\subsubsection{The window model of coarticulation}

The "window model of coarticulation" elaborated by Keating (1990) blurs this clear-cut distinction between the grammar and the physics of speech ${ }^{4}$. In Keating's view, the grammar has a phonological and a phonetic component. This phonetic component of the grammar has the function to specify whether a feature is relevant in the paradigm in a given language. For example, the voicing distinction is very systematic in English or German, but completely absent in Polish and Czech. This kind of facts has to be accounted for in the grammar. Altogether, there are three different ways to deal with underspecification: There is underspecification on the phonological level, which may persist in the phonetic domain. Then, there is phonetic underspecification which is conceptualized as a continuous notion. Additionally, unspecified features may be left unspecified or specified by rule. Now, if phonological assimilation rules assign a contextual feature to a segment, its associated window will be narrow before that context and the contour will have a plateau-like shape. If assimilation rules are not active, the key feature remains unspecified and the trajectories will be provided by "interpolation". Furthermore, inter-language differences in coarticulation can be of phonological or phonetic origin. If phonological assimilation rules operate in one language and not in the other, they are of phonological origin. They are of phonetic origin, if different languages interpret an unspecified feature differently.

\footnotetext{
${ }^{3}$ but see Lahiri \& Blumstein (1984).

${ }^{4}$ It has to be mentioned though that this clear-cut distinction between the grammar and the physics of speech has been abandoned earlier by approaches stemming from within featural phonology, e.g. in approaches as the theory of feature spreading (Hammarberg, 1976), the lookahead model, (Daniloff \& Hammarberg, 1973), the model of coarticulatory resistance Bladon \& Al-Bamerni (1976).
} 
In a different series of papers, Keating $(1988,1991,1993)$ elaborated the status of palatals and velars. In Keating (1988) it was proposed that palatals are complex segments involving both coronal and tongue body articulations, such that they would have a status like double-articulated labial-velars. The representation of the palatal has specifications on the dorsal as well as on the coronal node ${ }^{5}$ :

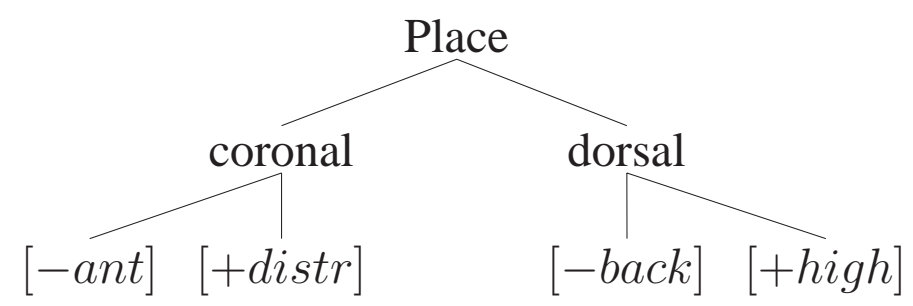

In yet another publication, Keating (1993) discusses the phenomena of velar fronting in terms of surface features for English:

With reference to the work of Houde (1968), she states that velars "lack inherent specification for Back ((Keating, 1991, p. 17))":

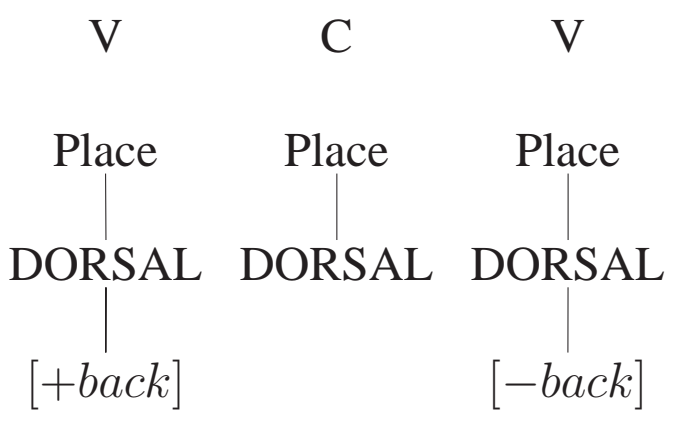

"Stated another way, velar fronting is something that happens gradually over the course of the velar. Such temporal/spatial variation, or phonetic gradience, can be interpreted as a transparency effect on the velar with respect to backness." (Keating, 1991, p. 17) This seems to tacitly assume a large "sliding" movement of the tongue during the closure interval, and, on the reverse, an absence of this kind of movements during the realization of the palatals. A point, which we will turn back on later.

For completeness, we reproduce the specification of the palatalized velars. In contrast to the velar specification cited above, palatalized velars have an inherent specification for Back.

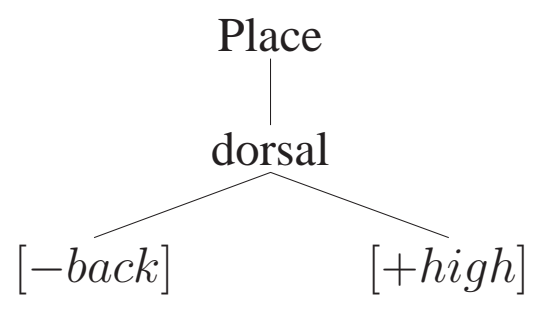

\footnotetext{
${ }^{5}$ Keating (1991) offers another possibility for the representation of palatals: "However, another option in the representation of palatals is to treat them as simple coronals, and introduce at least one additional feature to distinguish them from the [-anterior] coronals. This is in fact what Halle (1968) does with his new features Lower Incisors Contact. Actually, both options could be exercised for more descriptive coverage (Keating, 1991, p. 45)."
} 


\subsubsection{Coproduction theory and derivatives}

At this point, the necessity arises to review the very basic results of one of the most influential studies and the accompanying model of coarticulation: Öhman (1966) and Öhman (1967) proposed a model of vowel-to-vowel coarticulation, the basic empirical evidence of which was articulatory and acoustic analysis of Swedish VCV utterances produced in isolation, and similar speech material in American English and Russian. The material on the Russian data was different with regard to (secondary) palatalization. The major finding was that the consonantal transitions $\left(V_{1} C\right.$ and $\left.C V_{2}\right)$ depend on the identity of the transconsonantal vowel. But: this coarticulatory variability was reduced to almost random fluctuation in the case of Russian. Öhman interprets these findings as follows: The tongue is considered a system of independently operating articulators driven by invariant articulatory commands. The apical articulator is involved in the formation of apical consonants, the dorsal articulator in the formation of palatal and velar consonants and the tongue body articulator in the formation of vowels. The reduced coarticulatory variability for the palatalized F2-transitions is seen as the result of conflicting vowel commands on the tongue body, i.e. an [i]-like palatalization commands exerting a blocking effect on the following vowel.

On the basis of Öhman's work, the coproduction theory and articulatory phonology have been elaborated.

Fowler (1980) argues against speech production theories in general which take phonological features as input. The features used as input for the speech production mechanism are timeless, abstract and static and have to be translated into articulatory movement. As Farnetani \& Recasens (1999, p. 51) put it: "In this translation process, the speech plan supplies the spatial target and a central clock specifies when the articulators have to move." In contrast, Fowler's intention is to overcome this dichotomy and she suggests to modify the phonological units of the plan: The phonological units become dynamically specified phonetic gestures, with an intrinsic temporal dimension. In speech, these gestures are implemented by coordinative structures, i.e. by temporary functional dependencies among the articulators contributing to the goal the gestures want to achieve. For example, in producing a bilabial stop, a temporal functional link is created between upper lip, lower lip and jaw. Several gestures are allowed to be coproduced. The amount of articulatory variability induced by this coproduction depends on the degree to which the gestures involved share articulators. The case of minimal gestural interference is the production of $/ \mathrm{VbV} /$-sequences, where vocalic and consonantal constriction gestures involve two independent sets of articulators. Conversely, a "gesture is defined along exactly the same set of tract variables and articulators as the flanking vowels", if the consonant is a velar (Saltzman \& Munhall, 1989). However, the original work seems to make no reference to palatal articulation, but a series of papers by Recasens $(1997,2002)$ was explicitly designed to make these 
predictions $^{6}$ : The goal of the DAC(Degree of coarticulatory constraint)-scale attempts to characterize phonetic segments according to the types of articulatory constraints involved in their production. These values then can be used to predict the "coarticulatory resistance" of the segments. As in Fowler's theory, the DACmodel assumes that articulatory gestures associated with consecutive segments are coproduced and overlap to different degrees depending on their spatiotemporal properties, on prosodic factors and speech rate. According to DAC-scale, "consonants differ in DAC value according to the following order: dorsals (alveolopalatals, palatals, velars), lingual fricatives $(/ \mathrm{s} /, / \mathrm{J} /)$, dark $/ 1 /$, which can be assigned a maximum $\mathrm{DAC}$ value $(\mathrm{DAC}=3)$; dentals and alveolars such as $/ \mathrm{n} /$ and clear /1/ (DAC $=2)$; and bilabials, with the lowest DAC value $(\mathrm{DAC}=1)(\ldots)$ It is hypothesized that dorsal consonants are highly constrained based on the observation that their primary contact or constriction location stays relatively fixed in line with the large contact size involved and perhaps the sluggishness of the tongue dorsum. The same observation may even apply to velars provided that at least two targets in front and back vowel contexts are accounted for (Recasens, 2002)".

\subsection{Hypotheses}

To sum up the selected theories presented and predictions concerning palatals and velars:

1. Keating: Palatals -if the description as complex segments is not outdatedare dorsals and coronals likewise. This amounts to relatively little sensitivity to vowel-induced contextual coarticulation for palatals in contrast to velars. At the same time, front velars should be distinct from palatals in their shape configurations, velars lacking the /i/-like "component". If the surface underspecification Keating adopts for English is also valid for Hungarian velars, then the velars exhibit relatively large vowel-dependence in place of articulation. Furthermore, let us shortly review her statements on the phonetic implementation on contextual velar fronting: "Stated another way, velar fronting is something that happens gradually over the course of the velar". As mentioned, Keating seems to view this as a "transparency effect of the velar with respect to Backness.” (Keating, 1993, p. 17) . We need to add here, that this implies that this transparency effect should be absent over the the course of the palatal. Putting this together, according to Keating, velars and palatals should be distinguished by the amount of coarticulatorily induced variability and their behavior during these stops.

2. In contrast, Recasens (1990) rejects Keating's (1988) claim that palatals are complex segments produced with the blade and the tongue dorsum: "Contrary

\footnotetext{
${ }^{6}$ Recasens explicitly mentions his model as being a concrete instantiation of coproduction theory.
} 
to Keating, we believe that those consonants which have been characterized as alveolopalatals and front palatals in this paper belong to different articulatory classes. Moreover, front velars are back palatal articulations, and a mid palatal class is also needed in the light of the articulatory facts. (Recasens, 1990, p. 276)".

This implies the following predictions: Contextual fronting of velars should amount in a convergence with the tongue shapes of palatals. Furthermore, according to the DAC-scale presented above, palatals and velars should be equally prone to effects induced by variation of the vowel context.

The aim of this study is to tease apart these contradictory predictions by a comparison of the palatal and velar stops in Hungarian with respect to (a) vowel-contextspecific effects on tongue posture analyzed by factor-analytic techniques and (b) the vowel-context-specific movement patterns during the realization of these consonants.

\section{Method}

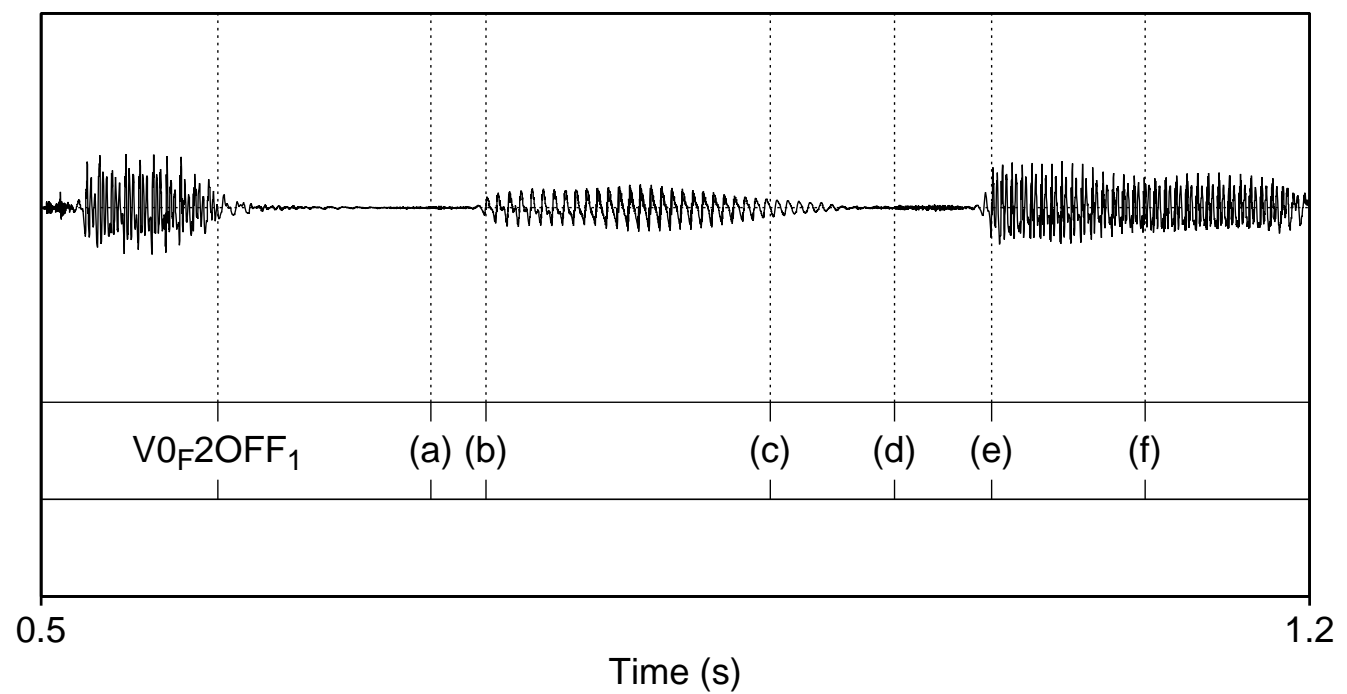

Figure 1. The figure shows an Illustration of segmentation criteria. For a more detailed description see text. The example sound is a voiceless palatal in the context of /i:/.

Tongue, jaw and lower lip movements of one female and two male speakers of Hungarian were recorded by means of Electromagnetic Midsagittal Articulography (EMMA, AG100, Carstens). The two male speakers natively were from Budapest, the female speaker came from the North of Hungary, from the region of Szeged. The choice of the Hungarian language arose from articulatory reasons, as the Hungarian palatal stops have been described as the palatal stops with the po- 
tentially strongest dorsal colouring (Keating \& Lahiri, 1993) ${ }^{7}$. Four sensors were attached to the tongue, one as far back as possible (TB), one approximately $1 \mathrm{~cm}$ behind the tongue tip (TT). The two middle sensors, tongue dorsum (TD) and tongue mid (TM) were located at equidistant points between them. Additional sensors were glued on the vermillion border of the lower lip (LLIP) and on the lower incisors (JAW). Two sensors on the nasion and on the upper incisors served as references for compensation of head movements relative to the helmet and definition of an intermediate coordinate system. The final coordinate system was defined by recordings of two sensors on a T-bar acquired in order to rotate the data to the occlusion plane for each speaker individually (Hoole, 1996). Original sample frequencies were $400 \mathrm{~Hz}$ for EMMA data and $48 \mathrm{kHz}$ for the acoustical signal. For the analysis, the EMMA signals were low-pass filtered and downsampled to $200 \mathrm{~Hz}$. The material consisted of $/ \mathrm{CVCa}$ / nonsense words with either velar or palatal voiceless stops as consonantal context and one of the long or short corner vowels $/ \mathrm{i}, \mathrm{a}, \mathrm{u} /$. Two realizations of the test words were embedded in the carrier sentence "Most a ... es a ... volt" ("This was a ... and a ... now") and repeated six to 10 times. The following temporal landmarks were extracted manually from the acoustic signal by means of the software package PRAAT by Boersma \& Weenink (1992-2004): (a) the burst of the initial consonant (b) the onset of the second formant of the first vowel, (c) the offset of the second formant of the first vowel, (d) the burst of the the medial vowel. (e) the onset of the second formant of the second vowel (f) the offset of the second formant of the second vowel. For the analyzes of the distances reported below -we will analyze the medial consonants of the $/ \mathrm{CVCa}$-sequences- four different intervals of the $\mathrm{VCa}$-sequence were defined: the movement from the midpoint of the first vowel to the onset of closure, where the midpoint of the vowel is defined as the central sample of the temporal landmarks of (b) and (c),the interval during closure defined as the time between (c) and (d)), the interval between the burst and voicing onset as the time between (d) and (e) and, the interval during the /a/,where the vowel mid of the second vowel is defined in analogy to the interval of the first vowel. These intervals serve as the basis for the articulatory analyzes reported below. In our opinion, the use of acoustic landmarks seems satisfied, because the commonly applied definition of articulatory landmarks from the speed signal was not consistently possible in all vowel environments. The distances traveled during the intervals defined above are calculated by summing the distances traveled by selected sensors over the course of these trajectories.

\footnotetext{
${ }^{7}$ As far as we can see, diachronically it has not emerged from velar palatalization: Palatals are a rather rare outcome of velar fronting (Bhat, 1978).
} 


\section{Results}

\subsection{Preliminary qualitative evaluation on palatal stop realisations in Hun- garian}

There was been a long-standing debate whether the palatal stop in Hungarian is a stop or an affricate (see Siptár \& Miklós (2000) for a summary). Realisations of the three speakers presented here showed yet another pattern: During the stop interval no full silence was achieved but the whole interval was accompanied by frication. Additional we found a portion which we interpreted as a (residual) burst. This was followed by a second frication portion with a change in the spectral energy distribution. Two more speakers have been recorded, one with and without EMMA. Preliminary inspection gave evidence of a clear palatal stop realisation. Since for the former speakers frication during the closure phase only occured for the palatal but not for the velar stop we assume that it is not an artefact of the recording procedure but a speaker-dependent allophonic variation. More thorough and detailed spectral analyses are needed before a conclusive categorisation of the observed patterns are possible.

\subsection{Positional data}

In the two top panels and the bottom left panel of fig.2, results of Principal Component analyzes of the covariance matrices of the averaged articulatory configurations excluding the lips during (a) the initial burst, (b) the medial burst and (c) the vowel configurations at the midpoint of V1 are shown. Principal component analysis (PCA) involves a decomposition of a a larger number of usually correlated variables into a (usually smaller) number of not directly observable uncorrelated variables. These are the so- called principal components. One drawback of these single-speaker factor solution is the fact of rotational indeterminacy, i.e. there exists an infinite number of solutions which explain the same amount of variance. In the bottom right panel of fig. 2, the solution of the multispeaker factors analytic model PARAFAC which avoids this problem is shown ${ }^{8}$.

The aim of both methods is to reveal new meaningful underlying variables, in our case, we can reduce the articulatory configuration containing separate $\mathrm{x}$ and y- positions for four tongue and one jaw sensor into a two-dimensional representation still representing the gross topology of the articulatory space analyzed. The first principal component accounts for as much of the variability in the data as

\footnotetext{
${ }^{8}$ PARAFAC is a type of multi-mode analysis procedure and therefore contrasting (PCA) or factor analysis, which are two mode representations. PARAFAC requires an at least threedimensional data structure with the third dimension usually being represented by different speakers, i.e. if all speaker weights are fixed to be one, then PARAFAC reduces to PCA. The advantage of PARAFAC is that there is no rotational indeterminacy as in PCA, in other words, PARAFAC gives unique results. The PARAFAC-model was introduced in experimental phonetics by Harshman et al. (1977).
} 


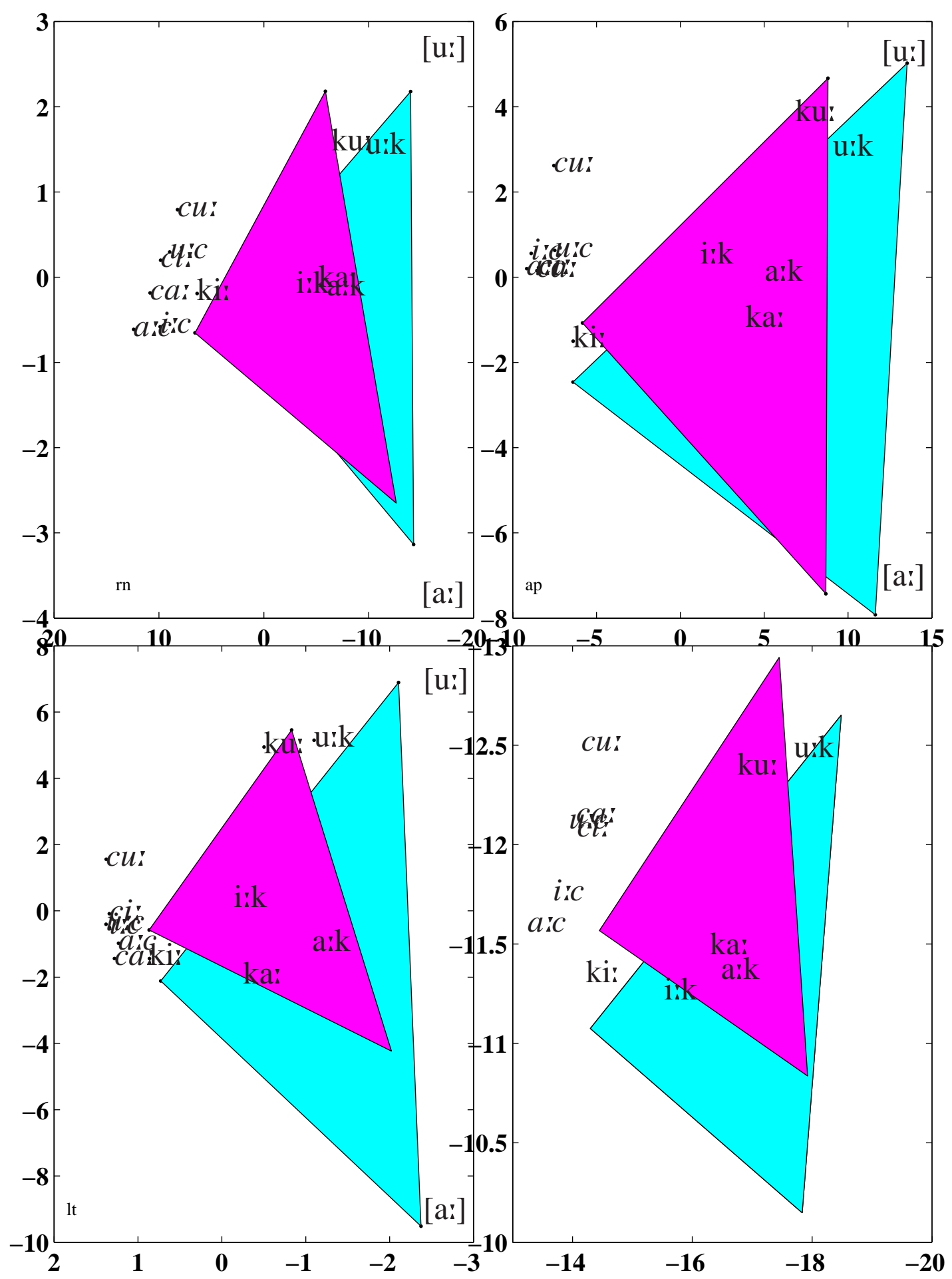

Figure 2. The two top panels and the lower left panel show speaker-dependent Principal Component analyzes of the mean tongue configurations at different temporal landmarks: the initial release, the medial release. The light gray triangles are the midpoints of the long corner vowels in the context of velar consonants, the dark gray triangles the corresponding projections of the long corner vowels in the palatal contexts. The lower right figure is a speaker-independent PARAFAC projection of the same data 

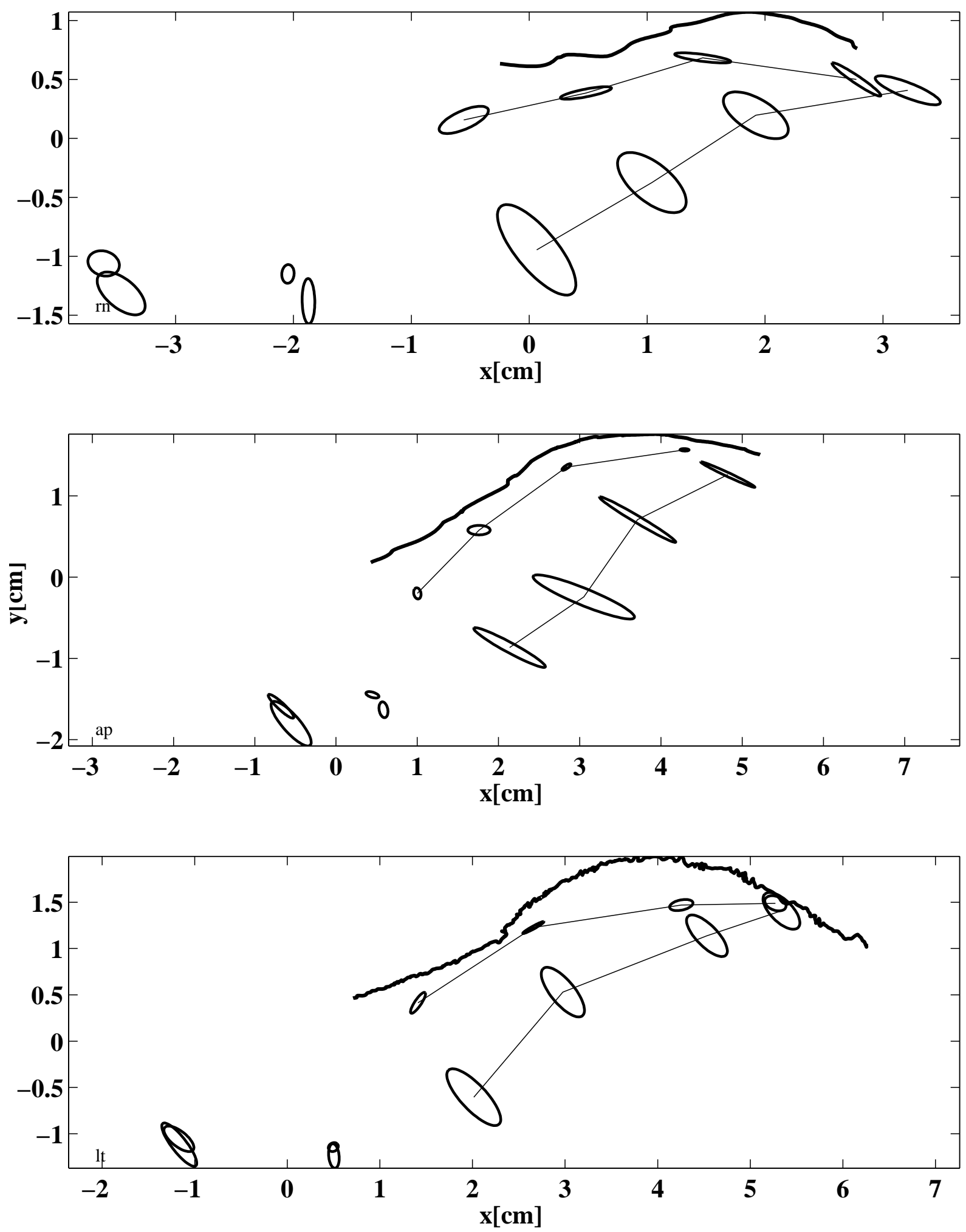

Figure 3. 1- $\sigma$-ellipses as indication for the variation of palatal and velar consonants as calculated by the means over all vowel contexts at burst time for initial and medial cononants. Small ellipses: Palatal configuration; large ellipses: velar configuration 
possible, and so does each succeeding component. For the single speaker Principal Component Analyses, the first factors explain between 65 and $80 \%$ of the variance and the second factors between 17 and $27 \%$. The total amount of variance varies between 93 and 98\%. This means that the most substantial portion of the variance is accounted for in the PCA representations, but the amount of variance explained is partitioned in different ways by different speakers. The grey "triangles" shown in fig. 2 are the vowel configurations at the midpoint of V1, with the dark grey triangle for the palatal context and the light grey triangle for the palatal context. The most salient pattern of all these plots seems that the velars show much more inclination to coarticulate with their vocalic environment in comparison with the palatals: For speakers ap and lt (top right and bottom left panel) all the palatals except the initial palatal in the context of /u:/ cluster close together, not far from the /i:/- edge of the "palatal triangle". Compared to the place variation for the velar stop this gives the impression of a stable palatal configuration very close to the first factor score of /i/. This finding is further substantiated by the plot of $1-\sigma$-ellipse shown in figure 3 . The velars substantially show more variation for all three speakers. ${ }^{9}$ In particular, only the second factor on the y-axis distinguishes between the palatals. The first factor is almost constant for the palatals and in line with the classic interpretation as "front-raising" to an /i/-like shape (Harshman et al., 1977). The most consistent pattern for the velars is that the shape of the velar in /u:/-context is close to the /u:/-corner. Of particular interest are the projections of the /i:/ in velar context and initial position. And here, the patterns do not seem to be fully conclusive: For ap, the $/ \mathrm{k} /$ is separated from the main palatal cluster as well as from the initial /c/ in /u:/-context. For speaker lt, the initial /k/ in /i:/-context is "dissolved" in the main palatal cluster. The same holds for speaker $/ \mathrm{rn} /$ although the whole single-speaker solution seems more diffuse than for the other speakers. So if we would have to be decisive about these factor solution, we would prefer to interpret the PARAFAC solution in the bottom right panel, because to be identified, certain assumptions have to be met: "The basic assumption is that, if a factor corresponds to some real organic unity, then from one study to another it will retain its pattern, simultaneously raising or lowering all its loadings according to the magnitude of the role of that factor under the different experimental conditions of the second study." (Cattell \& Cattell (1955), after Harshman \& Lundy, 1984, p.151). This means that this solution has to be judged higher in terms of its validity. This is substantiated in a clearer interpretability: The medial palatal consonants in /i:/- and /a:/-context show the strongest coarticulation with the vowel /i:/ in the palatal context, a finding that could have been expected. Then, there is a second palatal cluster with initial /i/ and /a/ and medial/u/-context. This analysis substantiates and enhances the finding of the initial palatal $/ \mathrm{u} /$ as having a

\footnotetext{
${ }^{9}$ One could raise the objection that the place of maximal constriction is not reliably measured even by the EMA tongue back sensors, but the parallel orientation of the ellipses for the rearmost sensor indicates that the constriction is mostly caught.
} 
bias towards the vowel /u/. And finally, the initial velar in /i/-context is the closest to the palatals of all velars. Moreover, another finding concerning the vowel triangles is remarkable: The sizes of the triangles are reduced in the palatal context, indicating, that the palatal consonants themselves exert a stronger coarticulatory influence on the vowels than the velars: in comparison with the velars, this results in a fronting of $/ \mathrm{u} /$ and a rising of the $/ \mathrm{a} /$.

\subsection{Kinematic Characteristics}

Figure 4 shows distances traveled during the four intervals which were defined earlier for the tongue dorsum sensor. Similar results were obtained for the tongue back sensor. The most salient aspect of these plots is that the total distances traveled by the TD sensor during the $/ \mathrm{VCa}$ /-sequences are larger in the palatal contexts for /a/ and /u/-contexts; the reverse holds for the /i/-contexts.

Concerning the velar contexts, we found some relatively surprising patterns in comparison with the data we analyzed earlier. In particular, in Geng et al. (2003) we found consistently bigger total amplitudes in the /a:-contexts. We interpreted this finding in agreement with Munhall et al. (1991), who observed a reduction in movement complexity after removing of the jaw influence. This tendency is weaker in this corpus and even reversed for speaker ap. So if the patterns for the /a/-contexts can at least partly be explained through a contribution of the jaw for both consonants, this explanation is not justified for the large total amplitudes for the palatals observed in the context of /u:/. If we cannot attribute these large movements to an influence of the jaw, then this pattern must be attributed to a strong movement component by the tongue itself. We will return to this point later. Another quite general observation in these plots is that the movement amplitudes during the stop, -i.e. the black parts of the bars- are usually larger for the velar consonants. This holds with the exception for the /a:/ and /u:/-contexts, where this finding is blurred, most probably due to large amplitudes aforementioned. Similar observations can be made for the distances traveled between the stop release and the onset of the second vowel /a/.

As a crude method for quantifying the direction the tongue paths travel during the closure interval, we weighted the distances the sensors traced in the closure interval by a "direction coefficient", which was determined as the sign function of the difference between the x-coordinates of the first sample of the closure interval and the last sample of the closure interval, i.e., negative values indicate the tendency to make a movement in backward direction during the closure. The error bars in figure 5 indicate the standard deviations of this composite for the tongue dorsum sensor. Again, similar results were obtained for the tongue back sensor. Note that this is a very gross measure, in particular, a mainly vertical movement during closure would have the consequence of making the sign function, which is only based on the horizontal movement in this interval relatively arbitrary. So note 

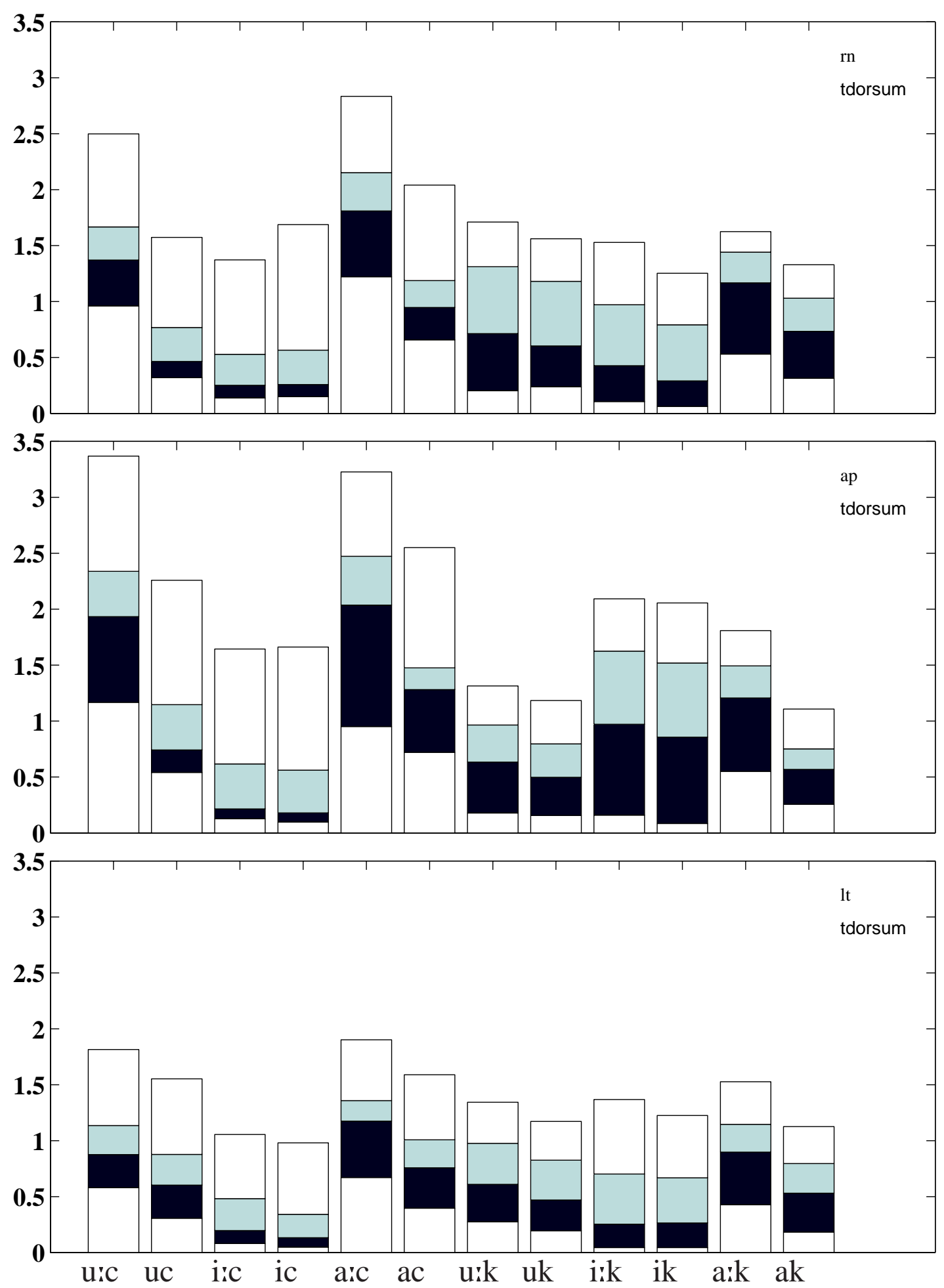

Figure 4. Distances the tongue dorsum sensor traveled during the four different intervals described. The stack bars indicate from bottom to top: first stack, white, distance traveled during the first vowel; second stack, black, distance traveled during oral closure; third stack, gray, distance traveled between stop release and the onset of the second vowel; fourth stack, white, distance traveled during the second vowel. Upper case characters: lax vowels, lower case: tense vowels. 

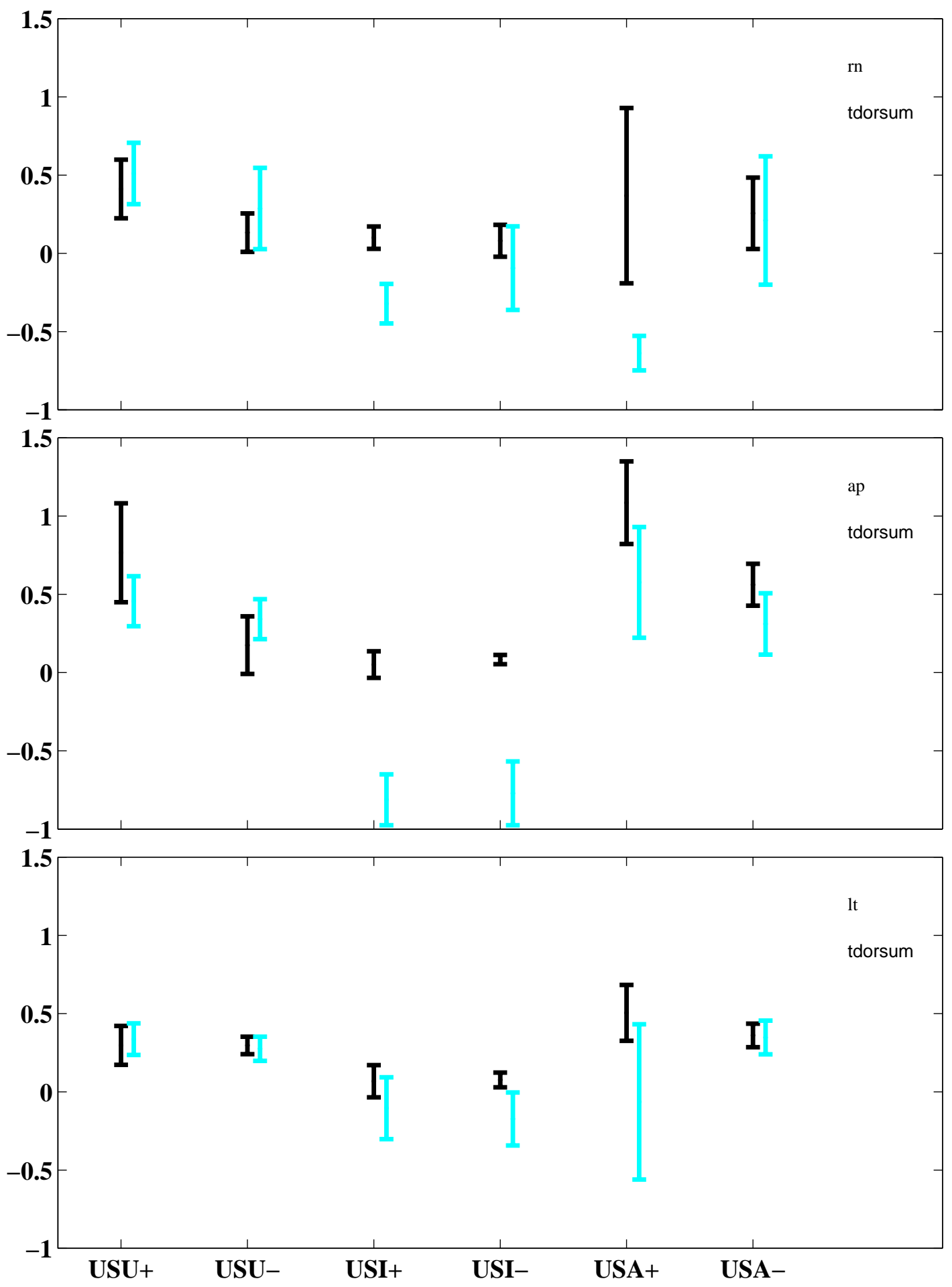

Figure 5. Distances the tongue dorsum sensor traveled during the the closure interval weighted by a direction coefficient. The direction coefficient was determined as the sign function of the difference between the first sample of the closure interval and the last sample of the closure interval, i.e., a negative value indicates the tendency to make a movement in backward direction during the closure. 
that the partially large standard deviations in these plots underlyingly might represent (a) heterogeneity in the true movement as an expression of token-to-tokenvariability or (b) the predominance of a vertical component causing a "noisy" sign function. So we will limit ourselves to the results which do not have this uncertainty and exclude the patterns which have large standard deviations and values above and below zero. For example, this concerns the results for speaker $1 \mathrm{t}$ in the context of /a:/: As due to the influence of the jaw, a vertical movement dominates, which results in a noisy sign function and therefore in large standard deviations.

Following the front vowel /i/ (long and short) and short/u/, very little movement was found during the palatal closure. A higher degree of forward movement occured during the palatal following long $/ \mathrm{u} /$ and $/ \mathrm{a} /$. For the velar stop movement during closure was consistently largest following long and short $/ \mathrm{u} /$. After /i/ two speakers showed almost no movement during / $/$ which is consistent with the data on German (Geng et a. 2003) and a relatively large backwards movement for speaker AP. Movement directions following long /a/ varied inter- and intraindividually (e.g. large standard deviations for speaker LT) These results indicate that the palatal stop is produced close to the constriction location for $/ \mathrm{i} /$, therefore no movement is required during closure.

Figures 6 shows the correlations between the positions in the mid of the first vowel and the distances traveled during the stops for tongue dorsum sensor. Again, similar tendencies were observed for the tongue back sensor. The left panel shows the correlation of distance and x-position and the right panel of distance and $y$ - position. For two out of our three speakers, the correlations for velar and palatal articulations have the same sign, i.e. the more anterior the sensor location during the following vowel, the larger the distance traveled during the stop closure (left panels), and, the higher the position of the sensor during the preceding vowel, the smaller the distance traveled during the preceding stop. Note that for RN and LT, the correlations between horizontal position and the distance traveled are spurious, only the height of the sensor during the preceding vowel seems to be related to the distance traveled during the stop. For one speaker, ap, the sign of the correlations is reversed for both sensors in the velar condition. This reverse in sign for the velar seems to contradict the results for German we presented in Geng et al. (2003). For the three speakers we presented there, no such sign reversal was observed $^{10}$, rather similar patterns to those of the other two speakers of this study were found.

\section{Discussion}

The results of this experiment can be summarized as follows:

\footnotetext{
${ }^{10}$ note that the vowel environment was richer in this study.
} 


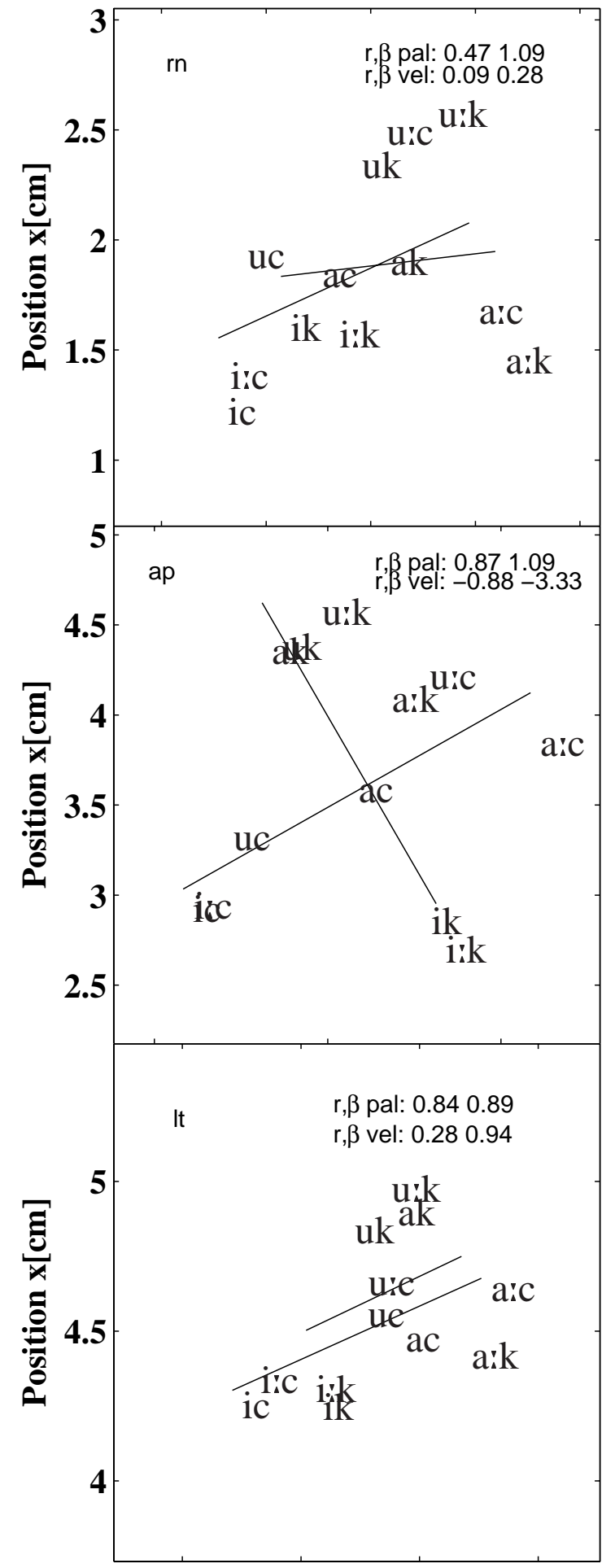

Distance during Closure [cm]

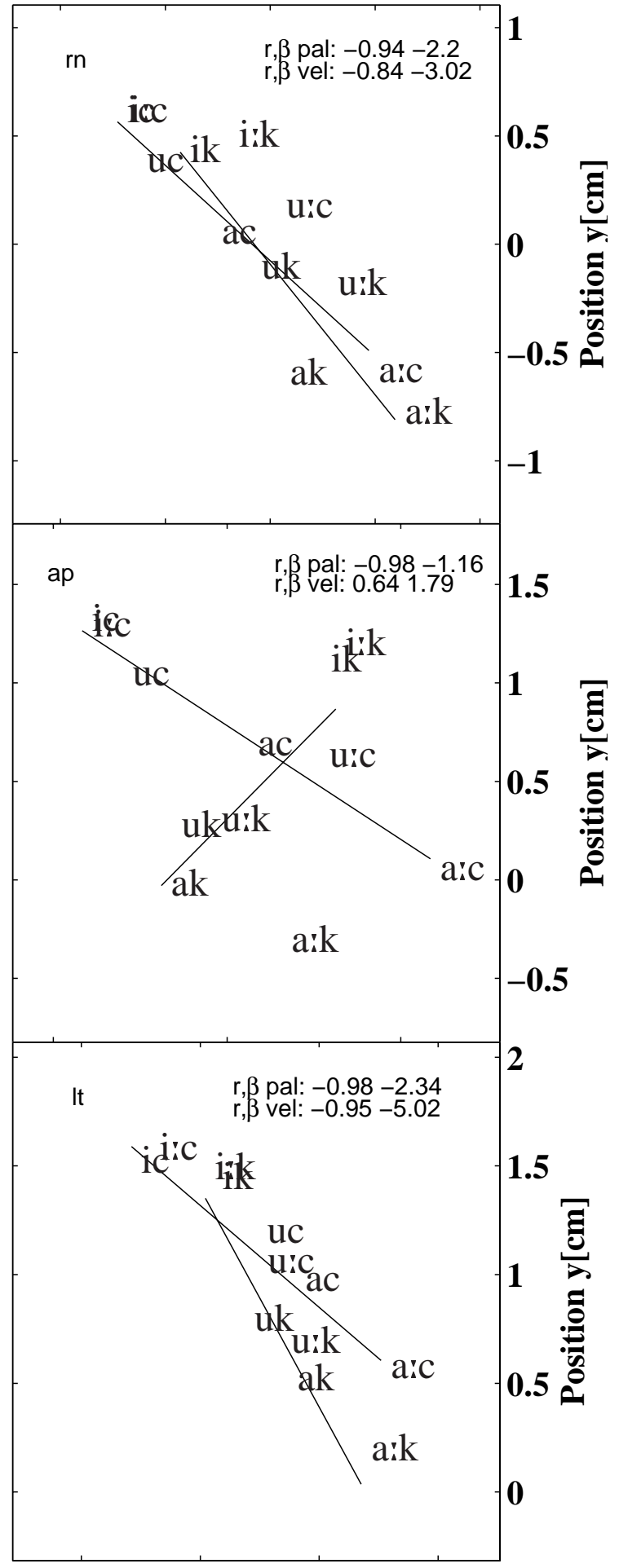

Distance during Closure [cm]

Figure 6. Correlations between the positions in the mid of the first vowel and the distances traveled during the stops, both for the tongue dorsum sensor. The left panel shows the correlation of distance and $\mathrm{x}$-position and the right panel of distance and $\mathrm{y}$-position. 
- Coarticulatory resistance of the palatal stop: Not very prone to vowel-like influences (a) the palatal itself exhibits a very stable configuration in comparison to the velar. This stable configuration is similar to an /i/-like shape (b) the palatal itself exerts an influence on the vowel articulation inasmuch as the size of the vowel space is shrunk in comparison to vowel space in the context of the velar stop.

- The initial palatal in the context of the back vowel /u:/ gets isolated from the relatively stable configuration we observed for the remaining palatals.

- Another important finding were the extremely large distances the palatal has to travel in the context of the long /u:/ over the whole VCV-sequence.

- For two out of our three speakers, the movement amplitude of the palatal in /u:/-context during closure is among the highest amplitudes altogether.

In the introductory section, we contrasted predictions about the gross coarticulatory variability patterns made by different approaches: Keating's approach creates its prediction from underspecification at different phonological or phonetic levels. This amounts to relatively little sensitivity to vowel-induced contextual coarticulation for palatals in contrast to velars if the derivations we used are the intended ones for the Hungarian language. In contrast, the DAC-scale by Recasens, adapting ideas from the theory of coproduction proposed by Fowler, predicts similar patterns in the tendency to coarticulate with the vowel environment for both palatals and velars: It assigns palatals and velars the same values on the DACscale. On this macro-level, Keating's approach makes better descriptions. Here, the necessity arises to summarize the influences Keating sees at work in shaping coarticulatory patterns. These are the following factors: (a) production constraints, operating both within and across languages,(b) contraints deriving from language-specific phonological structure and (c) language-particular contraints, unrelated to production or phonology and therefore unpredictable. Farnetani \& Recasens (1999, p.49) claim that cross-consonant differences and cross-language similarities in patterns of coarticulatory resistence (under-)specification held constant point to consonant-specific production constraints going beyond language peculiarities. We found the intial palatal stop in the context of /u:/ strongly coarticulating with the following vowel. We do not have cross-language data on palatal stops, but tried to relate this pattern to consonant-specific production constaints: To meet the objective of a palatal closure, the tongue has to travel a long distance in the context of /u:/. These were present in the form of long distances the tongue back and dorsum were moving. As these cannot be attributed to the influence of the jaw, we interpret them as consonant-specific production constraints for the palatal in back vowel context.

In the light of the data presented in this paper, Recasens' assignment of the same DAC-value for palatals and velars is unlikely because (a) the palatals themselves 
are articulated more consistently, and (b) they exert a bigger influence on the neigbouring vowel than the velars. For further substantiating our finding of a higher $\mathrm{DAC}$ value for the palatal we plan to analyse the postconsonantal vowel /a/ in the $/ \mathrm{CVCa}$ / sequences. If our hypothesis is true then the vowel /a/ should vary with the preceding medial vowel quality to a greater degree for the velar as compared to the palatal. In our view, several reasons could be responsible for the lack of fit to the data the DAC exhibits: One reason could lie in a too strong emphasis on the idea of the coupling of articulators neglecting a general articulatory movement economy aiming at the avoidance of long traveling paths. This might be augmented by Recasens' preference of the palatographic acquisition method, which does not take into account contacts behind the hard palate and also movements leading to tongue-palate contact.

A second important claim we elaborated in the introductory section is that articulatory velar fronting is a "transparency effect of the velar with respect to Backness" and "something that happens gradually over the course of the velar" as stated by Keating. She explicitly refers to Houde (1968), who first observed "sliding" movements over the course of velar consonants. If these sliding movements were an effect of surface underspecifications, then these movements should be unobservable over the course of palatals. This claim was strongly disconfirmed by our data: The movement amplitudes during the palatals, -especially in the context of the vowel /a/- can exceed the amplitudes in velar context. Note that these movements, beforehand only observed for the velars and called "loops" (see Mooshammer et al., 1995), have stimulated a whole research program in speech production as it has been seen as a paradigmatic case for the most different influences simultaneously shaping planning of the movement trajectory. Accordingly, several competing explanations were given for the phenomenon: The looping patterns are seen as a passive forward movement of the tongue due to airstream mechanisms Kent \& Moll (1972) or as a result of an active gesture aiming at the maintenance of voicing by Houde (1968), sometimes termed 'cavity enlargement' (Ohala, 1983). Löfqvist \& Gracco (2002) to explain looping patterns in more general principles of motor control, postulating the entire movement to be planned in terms of cost minimization principles. A recent modelling study by Perrier, Payan, Zandipour and Perkell (2003) emphasizes the role of tongue biomechanics. We think that palatal stops can essentially contribute to this research program.

We began the introduction with reference to the mechanisms that might underlie diachronic velar fronting ${ }^{11}$. Recasens (1990) argues that the front velar converges to a back palatal with respect to its articulatory configuration. Concerning this question, the results are ambiguous. While the speaker-independent factor solution and the single factor solution suggest a relatively strict separation in the shapes of the fronted velar and the palatal, this situation is ambiguous for

\footnotetext{
${ }^{11}$ let us note again here that the Hungarian palatal is probably not the output of velar fronting.
} 
the two other speakers. What we have more robustly, though, is the change in the articulatory configuration for the initial palatal stop in the context of /u:/, which we interpret as an excess of a threshold of maximum coarticulatory resistance. So if the diachronic process of velar palatalization has an articulatory grounding at all, this grounding could as well be afforded by a bidirectional articulatory change of contextual fronting of the velar and contextual backing of the palatal, rather than unidirectionally triggered by the velar.

\section{ACKNOWLEDGEMENT}

Work supported by German Research Council(DFG) grant GWZ 4/8-1, P.1

\section{References}

\section{References}

Bhat D. (1978). A general study of palatalization. In: J. Greenberg (ed.) Universals of Human Language. Vol. 2.: Phonology, 47-92. Stanford: Stanford University Press.

Bladon R. \& Al-Bamerni A. (1976). Coarticulation reistance in english /1/. Journal of Phonetics, 4:137-150.

Blumstein S. (1986). On acoustic invariance in speech. In: Invariance and Variability in Speech Processes, 179-197. Hillsdale, New Jersey, London: Lawrence Erlbaum Associates.

Blumstein S. \& Stevens K. (1979). Acoustic invariance in speech production: Evidence from measurements of the spectral characteristics of stop consonants. Journal of the Acoustical Society of America, 1001-1017.

Boersma P. \& Weenink D. (1992-2004). Praat, a system for doing phonetics by computer. www.praat.org. URL www. PRAAT . org.

Cattell R. \& Cattell A. (1955). Factor rotation for proportional profiles: analytical solution and an example. British Journal of Statistical Psychology, 8:83-92.

Daniloff R. \& Hammarberg R. (1973). On defining coarticulation. Journal of Phonetics, 1:239-248.

Farnetani E. \& Recasens D. (1999). Coarticulation in recent speech production theories. In: W.J. Hardcastle \& N. Hewlett (eds.) Coarticulation; Theory, Data and Techniques, 31-65. Cambridge: University Press.

Fowler C. (1980). Coarticulation and theories of extrinsic timing. Journal of Phonetics, 8:113-133. 
Geng C., Fuchs S., Mooshammer C., \& Pompino-Marschall B. (2003). How does vowel context influence loops? In: Proceedings of the SPS6: Sydney.

Guion G. (1998). The role of perecption in the sound change of velar palatalization. Phonetica, 55:18-52.

Hammarberg R. (1976). The metaphysics of coarticulation. Journal of Phonetics, 4:353-363.

Harshman R., Ladefoged P., \& Goldstein L. (1977). Factor analysis of tongue shapes. Journal of the Acoustical Society of America, 693-707.

Harshman R. \& Lundy M. (1984). Data preprocessing and the extended parafac model. In: H. Law (ed.) Research Methods for Multimode Data Analysis, 216284. New York: Prager.

Hoole P. (1996). Issues in the acquisition, processing, reduction and parameterization of articulographic data. Forschungsberichte des Instituts für Phonetik und Sprachliche Kommunikation der Universität München, 34:158-173.

Houde R. (1968). A study of tongue body motion during selected consonant sounds. Speech Communications Research Laboratory, Santa Barbara,SCRL Monograph 2.

Keating P. (1993). Phonetic representation of palatalization versus fronting. UCLA Working Papers in Phonetics, 85:6-21.

Keating P. \& Lahiri A. (1993). Fronted velars, palatized velars, and palatals. Phonetica, 73-101.

Keating P.A. (1988). Palatals as complex segments: X-ray evidence. UCLA Working Papers in Phonetics, 69:77-91.

Keating P.A. (1990). The window model of coarticulation: articulatory evidence. In: J. Kingston \& M.E. Beckman (eds.) labphon1, 451-470. Cambridge: Cambridge University Press.

Keating P.A. (1991). Coronal places of articulation. In: C. Paradis \& J.F. Prunet (eds.) Phonetics and Phonology 2: The special status of coronals: Internal and external evidence, 29-48. Academic Press.

Kent R. \& Moll K. (1972). Cinefluographic analyses of selected lingual consonants. Journal of Speech and Hearing Research, 15:453-473.

Lahiri A. \& Blumstein S.E. (1984). A re-evaluation of the feature coronal. Journal of Phonetics, 12:133-146.

Lindblom B., Guion S., Hura S., Moon S., \& Willerman R. (1995). Is sound change adaptive? Rivista di linguistica, 7:5-37. 
Löfqvist A. \& Gracco V.L. (2002). Control of oral closure in lingual stop consonant production. Journal of the Acoustical Society of America, 111:2811-2827.

Mooshammer C., Hoole P., \& Kühnert B. (1995). On loops. Journal of Phonetics, 23:3-21.

Munhall K., Ostry D., \& Flanagan J. (1991). Coordinate spaces in speech planning. Journal of Phonetics, 19:293-307.

Ohala J.J. (1983). The origin of sound patterns in vocal tract constraints. In: P.F. MacNeilage (ed.) The production of speech, 189-216. New York: Springer.

Ohala J.J. (1993). The phonetics of sound change. In: C. Jones (ed.) Historical linguistics: Problems and perspectives, 237-278. London: Longman.

Öhman S. (1967). Numerical model of coarticulation. Journal of the Acoustical Society of America, 41:310-320.

Öhman S.E.G. (1966). Coarticulation in VCV utterances: Spectrographic measurements. Journal of the Acoustical Society of America, 39:151-168.

Perrier P., Payan Y., Zandipour M., \& Perkell J. (2003). Influences that shape tongue biomechanics on speech movements during the production of velar stop consonants: A modeling study. Journal of the Acoustical Society of America, 114:1582-1599.

Recasens D. (1990). The articulatory characteristics of palatal consonants. Journal of Phonetics, 18:267-280.

Recasens D. (1997). A model of lingual coarticulation based on articulatory constraints. Journal of the Acoustical Society of America, 102:544-561.

Recasens D. (2002). An ema study of vcv coarticulatory direction. Journal of the Acoustical Society of America, 111:2828-2840.

Recasens D. (2003). Articulation and sound change in romance. In: Proceedings of the 15th International Congress of Phonetic Sciences, 231-234.

Saltzman E. \& Munhall K. (1989). A dynamical approach to gestural patterning in speech. Haskins Status Report on Speech Research, 99/100:38-68.

Siptár P. \& Miklós T. (2000). The phonology of Hungarian. Oxford: Oxford Univ. Press. 